\title{
Spontaneous Regression of Clear Cell Carcinoma of the Endometrium
}

\author{
Ketevani Kankava ${ }^{1 *}$, Alexi Baidoshvili², Eltjo Schutter ${ }^{3}$, Sytske Van der Meer ${ }^{4}$, David Makaridze ${ }^{2}$ \\ ${ }^{1}$ Department of Pathology, N. Kipshidze Central University Clinic, Tbilisi, Georgia \\ ${ }^{2}$ Department of Pathology, Laboratory of Pathology Oost Nederland, Hengelo, The Netherlands \\ ${ }^{3}$ Department of Obstetrics \& Gynaecology, Medisch Spectrum Twente, Enschede, The Netherlands \\ ${ }^{4}$ Department of Psychiatry, Mediant Locatie Helmerzijde, Enschede, The Netherlands \\ Email: *keti_kankava@yahoo.com
}

How to cite this paper: Kankava, K., Baidoshvili, A., Schutter, E., Van der Meer, S. and Makaridze, D. (2016) Spontaneous Regression of Clear Cell Carcinoma of the Endometrium. Journal of Cancer Therapy, 7, 635-645.

http://dx.doi.org/10.4236/jct.2016.79066

Received: April 25, 2016

Accepted: September 3, 2016

Published: September 6, 2016

Copyright $\odot 2016$ by authors and Scientific Research Publishing Inc. This work is licensed under the Creative Commons Attribution International License (CC BY 4.0).

http://creativecommons.org/licenses/by/4.0/

\begin{abstract}
This report documents a rare case of complete spontaneous regression of clear cell carcinoma of the endometrium. An elderly woman with paranoid schizophrenia was admitted to the hospital because of vaginal bleeding. Diagnostic curetting and biopsy were performed and she was diagnosed with clear cell carcinoma of endometrium. Anti-tumour therapy was not possible because of her poor psychiatric status. 13 months later the woman died of a natural cause and at autopsy the endometrial tumour could no longer be identified. Myocardial infarction, aggravated by poor functional status of organism due to sepsis, was concluded to be the cause of death.
\end{abstract}

\section{Keywords}

Gynaecological Cancer, Pathology, Spontaneous Regression, Clear Cell Carcinoma, Endometrial Cancer, Glucose Metabolism

\section{Background}

Spontaneous regression of a malignant tumour is a rare and incompletely understood phenomenon. It is defined as complete or partial disappearance of tumour without medical treatment, considered to be adequate for tumour disappearance.

The knowledge around this topic is mainly based upon individual case reports. Due to this event happening extremely rare (the incidence of spontaneous regression has been estimated to be not more than 1 in 60,000 - 100,000 patients) [1], there are no proven data about the mechanism or inducing factors. But the fact that spontaneous regression of cancer can occur is recognized and undisputed. Several attempts of putting the reported cases of spontaneously regressing cancers have been done [2]-[4]. 
According to them, reasons and mechanisms of these regressions are still ambiguous and majority of case report authors cannot provide a possible cause of spontaneous regression. The factors that are supposed to be responsible for spontaneous regression include surgical interventions, immunological factors, tumour necrosis, apoptosis, epigenetic mechanisms, endocrine factors, carcinogen inactivation, psychological factors and effects of some drugs, not directly acting against cancer tissue. On cellular level the induction of spontaneous regression is completed by either cell differentiation or cell death [5]. In some cases tumour regression was preceded by surgical procedures [6][8]; the role of infectious agents and febrile reaction [9]-[13] as well as changes in metabolic processes (especially glucose metabolism) [14] [15] in the regression of cancer is also well documented.

\section{Case Presentation}

An elderly Caucasian woman with paranoid schizophrenia, diabetes mellitus type 2 and hypertension presented with vaginal bleeding. Her condition was continuously monitored and no other remarkable information was present in her medical history. Under general anaesthesia a gynaecological examination was performed. During examination bulky and necrotic masses, closely resembling tumour, were found in the vagina and were removed. At the same time curettage was carried out and biopsy was taken from the endometrium.

A computer tomography scan revealed: Uterine corpus size in the sagittal plane was $72 \times 55 \mathrm{~mm}$, slightly non-homogeneous and contained several small calcifications. At the level of the cervix a mass with enlargement of diameter up to approximately $4 \mathrm{~cm}$ was described (Figure 1(a)). Invasive growth from the uterus or cervix into surrounding structures was not seen. There was no free fluid present in pelvic cavity (Figure $1(\mathrm{~b})$ ).

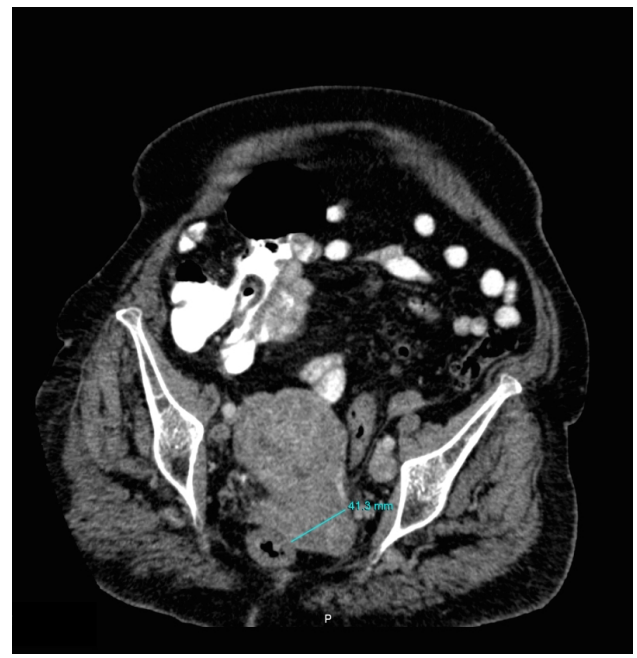

(a)

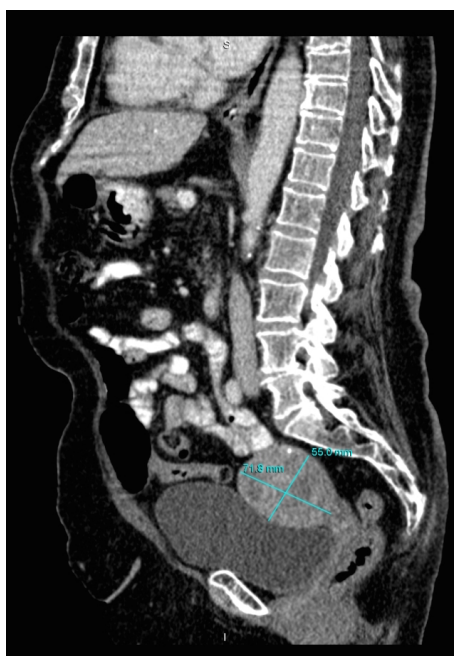

(b)

Figure 1. (a) and (b) Computer tomography image of the uterine mass. The measurements are given. 
Histological evaluation of all specimens, removed from cervical cavity and obtained by biopsy revealed epithelial solid fields and cribriform areas of cells with enlarged nuclei and prominent nucleoli, atypical mitoses, partly eosinophilic and mostly significantly clear cytoplasm. Clear cell component was seen in $50 \%-70 \%$ of the tumour (Figure 2).

The Periodic acid-Schiff (PAS) staining for glycogen was positive (Figure 3), and $\mathrm{Pe}$ riodic acid-Schiff-diastase (PAS-D) staining for mucus was negative (Figure 4).

Immunohistochemical staining showed, that the tumour cells were diffusely positive for monoclonal antibodies against pancytokeratin (AE1/AE3) (Figure 5), cytokeratin 7 was positive in $5 \%$ of tumour cells (Figure 6), other markers, which showed immunoreactivity: EMA (5\%), RCC-smp314 (30\%), CA-125 (30\%), p53 (was expressed weakly) (Figure 7), AMACR (diffuse positivity), CD10 (50\%), Cyclin D1 (40\% - 50\%) and bcl-2. The tumour cells were negative for Vimentin (Figure 8), WT1 (Figure 9), Cytokeratin 20, ER/PR, CEA (Figure 10), TTF-1, CD57.

The final diagnosis was clear cell carcinoma of endometrium. Although relying on

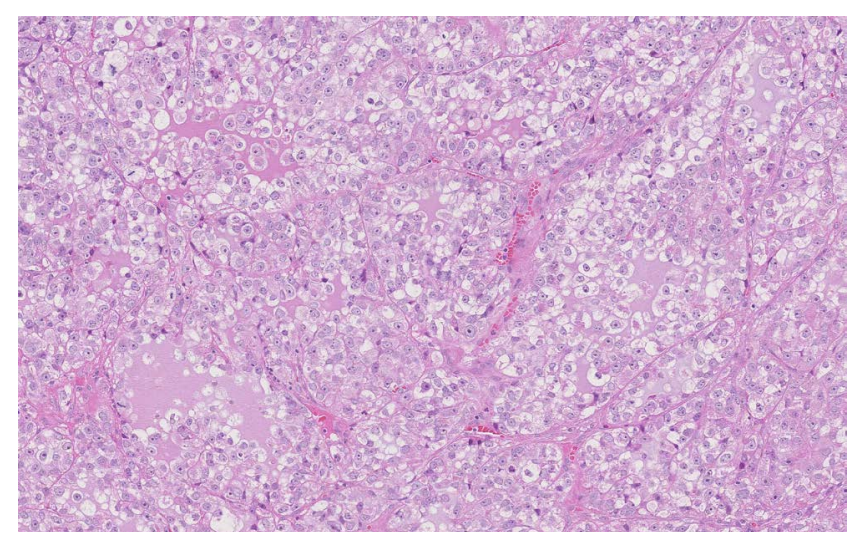

Figure 2. Microscopic appearance of the endometrial tissue from curetting specimen-clear cell carcinoma, hematoxilin and eosin (H\&E) staining, $\times 10$.

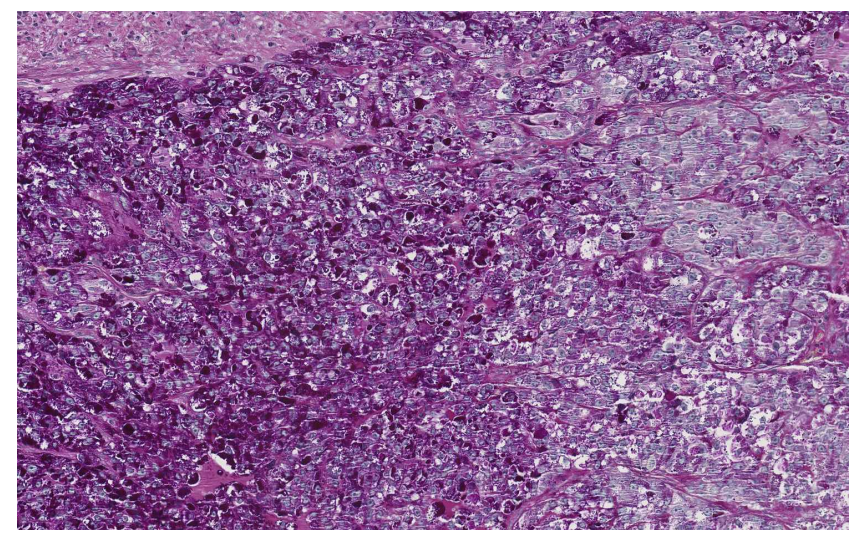

Figure 3. Microscopic appearance of the endometrial tissue from curetting specimen-clear cell carcinoma, Periodic AcidSchiff (PAS) staining, $\times 10$. 


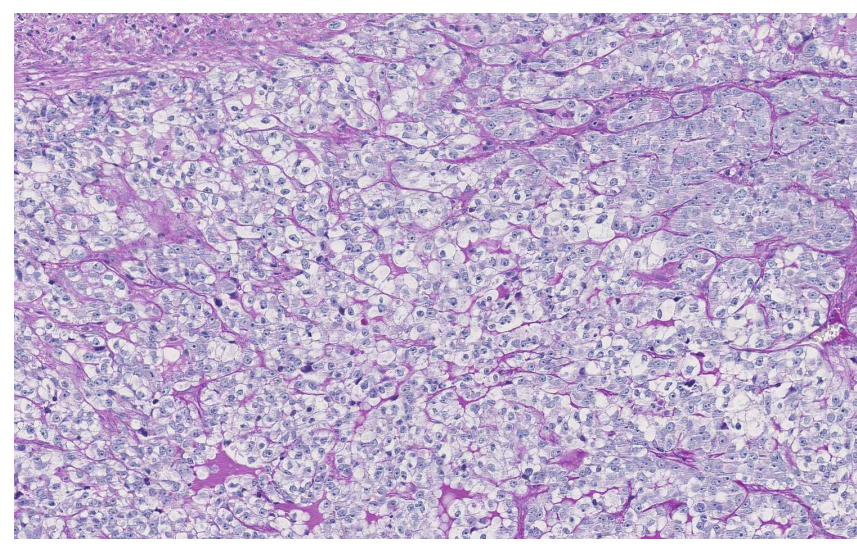

Figure 4. Microscopic appearance of the endometrial tissue from curetting specimen-clear cell carcinoma, Periodic Acid-Schiffdiastase (PAS-D) staining, $\times 10$.

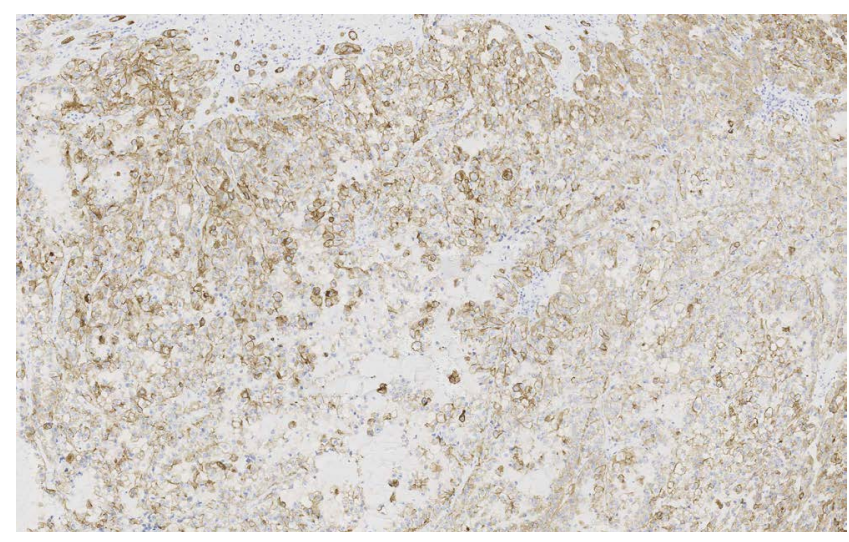

Figure 5. Microscopic appearance of the endometrial tissue from curetting specimen-clear cell carcinoma, immunohistochemical staining with monoclonal antibodies against pancytokeratins AE1/AE3, $\times 10$.

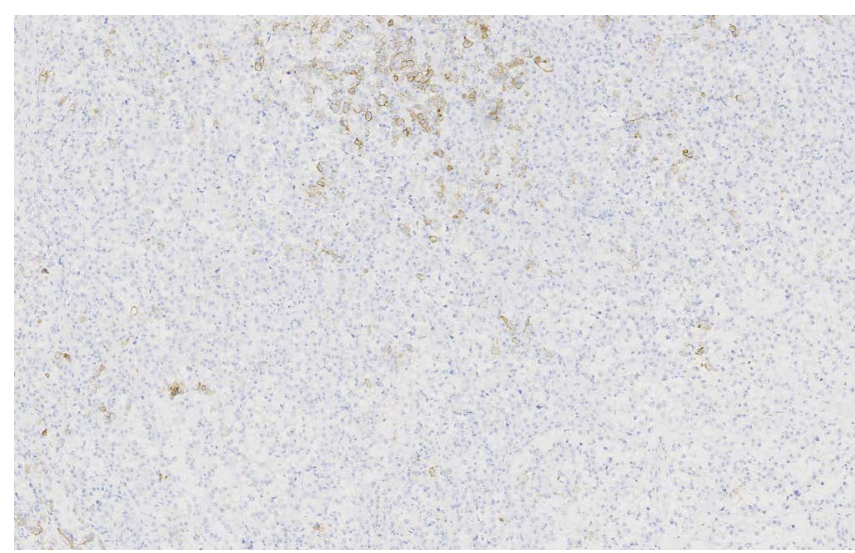

Figure 6. Microscopic appearance of the endometrial tissue from curetting specimen-clear cell carcinoma, immunohistochemical staining with monoclonal antibodies against cytokeratin CK7, $\times 10$. 


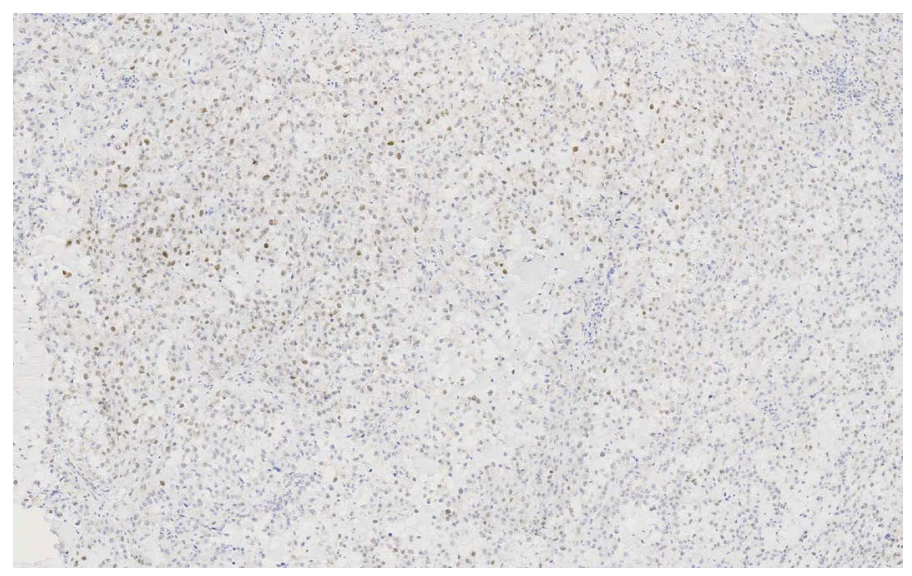

Figure 7. Microscopic appearance of the endometrial tissue from curetting specimen-clear cell carcinoma, immunohistochemical staining with monoclonal antibodies against p53, $\times 10$.

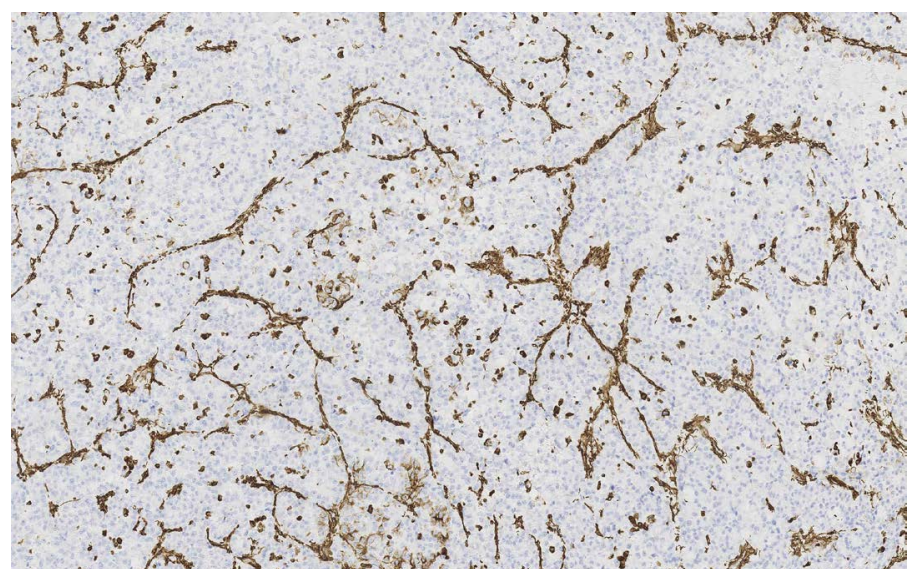

Figure 8. Microscopic appearance of the endometrial tissue from curetting specimen-clear cell carcinoma, immunohistochemical staining with monoclonal antibodies against Vimentin, $\times 10$.

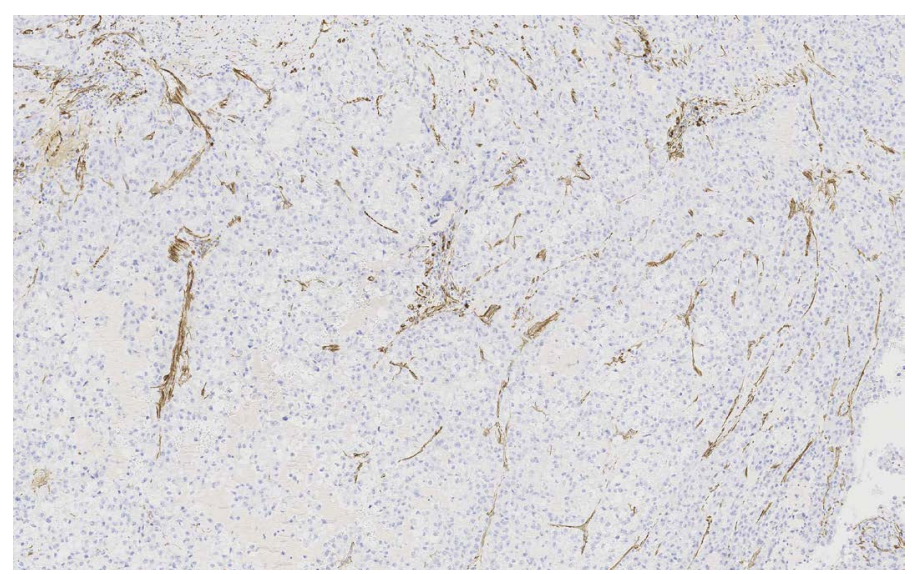

Figure 9. Microscopic appearance of the endometrial tissue from curetting specimen-clear cell carcinoma, immunohistochemical staining with monoclonal antibodies against WT1, $\times 10$. 


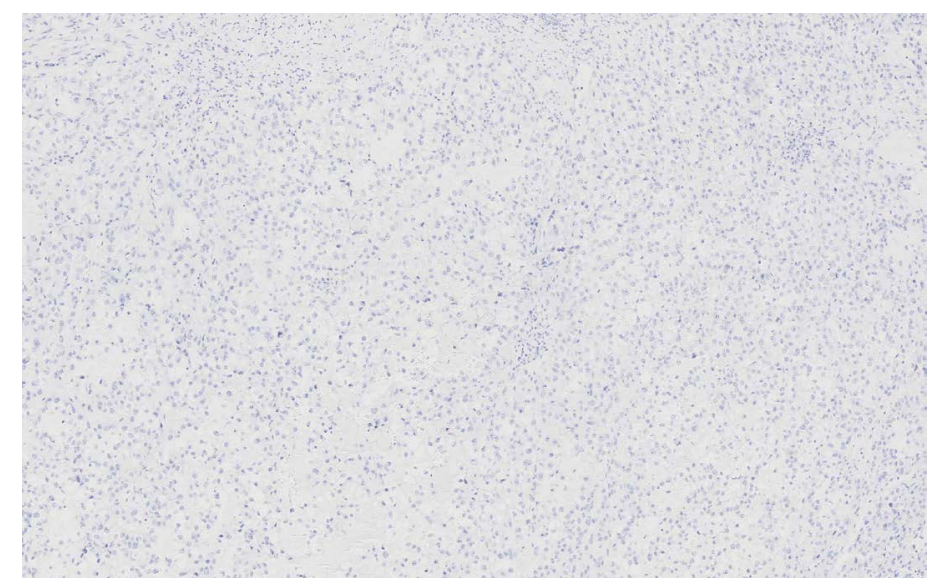

Figure 10. Microscopic appearance of the endometrial tissue from curetting specimen-clear cell carcinoma, immunohistochemical staining with monoclonal antibodies against CEA, $\times 10$.

immunohistochemical pattern a definite differentiation between clear cell carcinoma of endometrium and endocervix was not possible. But endocervical cancer would be expected to be CEA positive. Primary ovarian carcinoma was less probable because of WT1 negativity.

Taking into consideration the general condition of the patient, neither surgical, nor chemo-radiotherapy was considered possible.

After the gynaecologic examination with removal of the bulky masses the general condition of the patient improved. No episodes of vaginal bleeding were reported. The patient continued treatment with psychotropic drug (Risperdal $2 \mathrm{mg}$ ) and continuously received Metformin.

No further follow-ups were possible due to the psychiatric condition of the patient.

13 months later the patient died. The pathologist performed an autopsy in attendance of the treating psychiatrist. At autopsy extensive areas of necrotizing inflammation and abscess were found in liver (Figure 11). Sepsis and bacteraemia were confirmed. In addition there were multiple inflammatory areas around the pancreas. A focus of myocardial infarction (weeks or months old) was detected with extensive atherosclerosis of coronary arteries. No carcinoma could be found in uterine corpus or cervix (Figures 12-14). Only presence of adenomyosis and leiomyoma was described in uterine corpus. Myocardial infarction, aggravated by poor functional status of organism due to sepsis, was concluded to be a cause of death.

\section{Discussion}

Although the precise mechanism of tumour regression is unknown, our case demonstrates that clear cell carcinoma of the endometrium may spontaneously regress.

The possibility that the tumour was completely removed by combination of manual removal, curettage and biopsy is unlikely because in the histological specimens only tumour was seen without any fragment of normal endometrial tissue. Several mechanisms of tumour regression can be discussed to explain this case. 


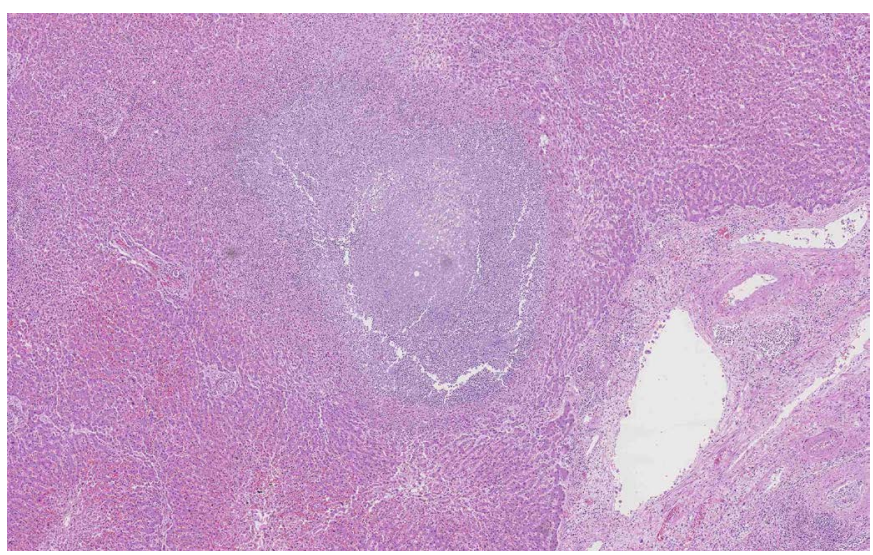

Figure 11. Microscopic appearance of the liver tissue from postmortem examination, $\mathrm{H} \& \mathrm{E}$ staining, $\times 2.5$.

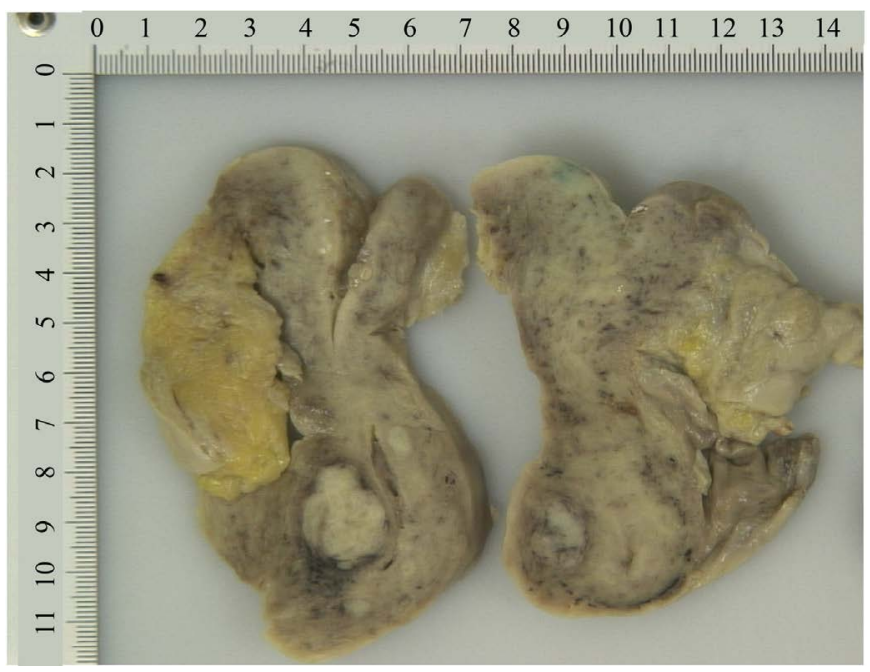

Figure 12. Macroscopic appearance of uterine cervix and corpus from gross examination of post-mortem specimen.

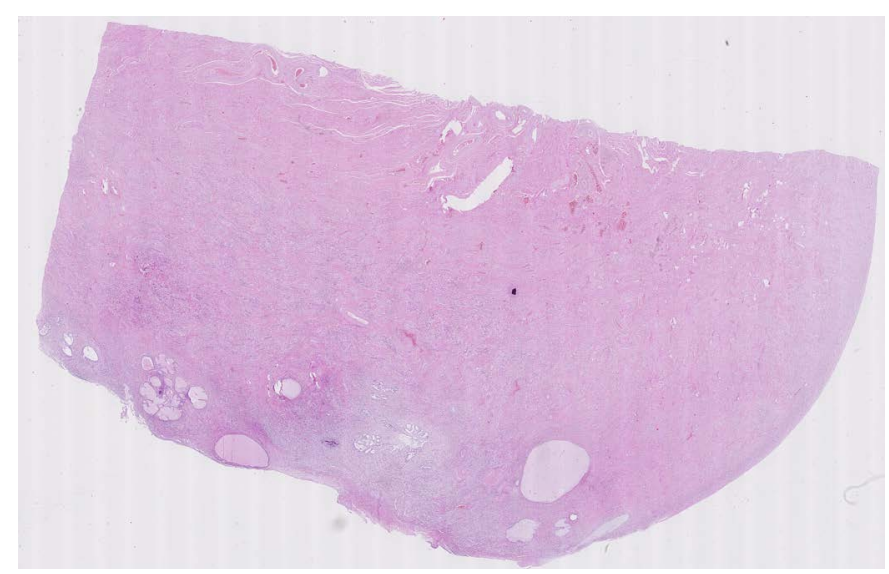

Figure 13. Microscopic appearance of the cervical tissue from post-mortem examination-no pathological changes, H\&E staining, $\times 1.25$. 


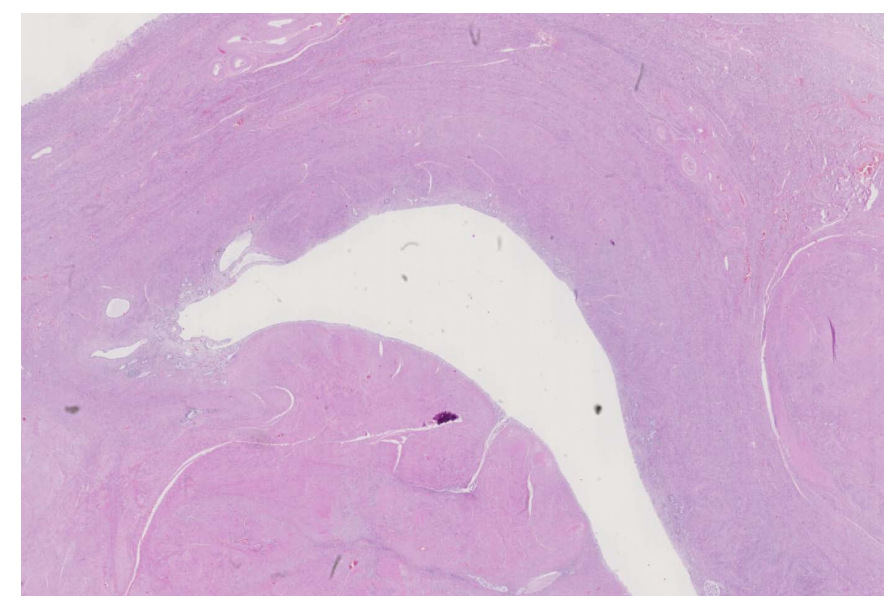

Figure 14. Microscopic appearance of the endometrial and myometrial tissue from post-mortem examination-uterine leiomyoma is seen, $H \& E$ staining, $\times 1.25$.

Described cases of tumour regression explained with usage of similar psychotropic drug, to that used in treatment of this particular patient couldn't be found in the literature. Investigations around the possible mechanism for Risperdal to induce cancer regression were also not successful.

There is convincing evidence of glucose metabolism and factors affecting it being important for tumour cell survival, progression and regression of tumours [16]-[18]. One recent study has suggested using ketogenic diet in combination with metformin as a potential treatment for cancer diseases [19]. Some studies suggest that metformin may also target the inflammatory component present in the microenvironment of most neoplastic tissues, leading to tumour reduction. In addition, inhibition of neoplastic angiogenesis by metformin might also participate in the reduction of tumour growth [20] [21]. Another study on breast cancer states that metformin has an ability to selectively kill cancer stem cells and to function synergistically with chemotherapeutic agents to block both cancer stem cells and non-stem transformed cells [22]. Other researchers have also come to similar conclusions [23] [24].

It may be possible that the tumour regressed as a reaction of the body to dissemination of tumour cells via the blood and lymphatic vessels. Such dissemination may produce a sudden tumour-antigen load of sufficient magnitude to stimulate a substantial anti-tumour immune response. There have been several reports of such effect, for example, post-fine needle aspiration biopsy necrosis of thyroid tumours [1] [25].

The role of infectious agents in the regression of cancer may also be a possibility. Bacteraemia, necrotizing inflammation and abscesses may have been a reason of tumour regression by activating whole cascade of potential anti-tumoral processes [26]. In addition bacterial endotoxins increase lymphocyte activity, stimulate the secretion of tumour necrosis factor and suppress the formation of new blood vessels, which are vital for the growth of tumour [9] [10]. There are reports about remission in leukemia, associated with pyogenic infections [27]. In a syngeneic mouse model pancreatic cancer has 
been found to regress in response to intratumoural injections of living Streptococcus pyogenes [11].

Other popular hypotheses to explain tumour regression include changes in diet, intake of nutritional supplements, herbal medications, hormones and steroids. In our case the role of these factors is extremely unlikely.

There are a small number of cases of spontaneously regressing gynaecological malignancies reported [3] [28]. Although Everson reported two cases of endometrial carcinoma with spontaneous regression, none of them demonstrated long-term survival [2]. One more case was documented by Beller et al. [29]. A 56-year-old woman was alive without recurrent disease 18 years from primary diagnosis. Another case was described by Parker et al. [30]. A 73-year-old woman with essential thrombocytosis and metastasized clear cell endometrial carcinoma received no therapy and remained disease-free 6 years later.

\section{References}

[1] Cole, W.H. (1981) Efforts to Explain Spontaneous Regression of Cancer. Journal of Surgical Oncology, 17, 201-209. http://dx.doi.org/10.1002/jso.2930170302

[2] Everson, T.C. and Cole, W.H. (1966) Anonymous Spontaneous Regression of Cancer. Saunders, Philadelphia, 1-10, 164-220.

[3] O’Regan, B. and Hirschberg, C. (1993) Spontaneous Remission. An Annotated Bibliography. Institute of Noetic Sciences, Sausalito.

[4] Challis, G.B. and Stam, H.J. (1990) The Spontaneous Regression of Cancer. A Review of Cases from 1900 to 1987. Acta Oncologica, 29, 545-550.

http://dx.doi.org/10.3109/02841869009090048

[5] Papac, R.J. (1998) Spontaneous Regression of Cancer: Possible Mechanisms. In Vivo, 12, 571-578.

[6] Sindelar, W.F. (1976) Regression of Cancer Following Surgery. Journal of the National Cancer Institute Monographs, 44, 81-88.

[7] Dao, T.L. (1962) Regression of Pulmonary Metastases of a Breast Cancer. Archives of Surgery, 84, 574-577. http://dx.doi.org/10.1001/archsurg.1962.01300230090017

[8] Abdelrazeq, A.S. (2007) Spontaneous Regression of Colorectal Cancer: A Review of Cases from 1900 to 2005. International Journal of Colorectal Disease, 22, 727-736. http://dx.doi.org/10.1007/s00384-006-0245-Z

[9] Thotathil, Z. and Jameson, M.B. (2007) Early Experience with Novel Immunomodulators for Cancer Treatment. Expert Opinion on Investigational Drugs, 16, 1391-1403. http://dx.doi.org/10.1517/13543784.16.9.1391

[10] Thomas-Tikhonenko, A. and Hunter, C.A. (2003) Infection and Cancer: The Common Vein. Cytokine \& Growth Factor Reviews, 14, 67-77. http://dx.doi.org/10.1016/S1359-6101(02)00071-0

[11] Malezki, C., Linnebacher, M., Reikemeyer, B. and Emmrich, J. (2008) Pancreatic Cancer Regression by Intratumoural Injection of Live Streptococcus pyogenes in a Syngeneic Mouse Model. Gut, 57, 483-491. http://dx.doi.org/10.1136/gut.2007.125419

[12] Hoption Cann, S.A., van Netten, J.P. and van Netten, C. (2003) Dr William Coley and Tumour Regression: A Place in History or in the Future. Postgraduate Medical Journal, 79, 672-680. 
[13] Jessy, T. (2011) Immunity over Inability: The Spontaneous Regression of Cancer. Journal of Natural Science, Biology and Medicine, 2, 43-49. http://dx.doi.org/10.4103/0976-9668.82318

[14] Bowker, S.L., Yasui, Y., Veugelers, P. and Johnson, J.A. (2010) Glucose-Lowering Agents and Cancer Mortality Rates in Type 2 Diabetes: Assessing Effects of Time-Varying Exposure. Diabetologia, 53, 1631-1637. http://dx.doi.org/10.1007/s00125-010-1750-8

[15] Hamanaka, R.B. and Chandel, N.S. (2012) Targeting Glucose Metabolism for Cancer Therapy. JEM, 209, 211-215. http://dx.doi.org/10.1084/jem.20120162

[16] Oleksyszyn, J., Wietrzyk, J. and Psurski, M. (2014) Cancer: Could It Be Cured? A Spontaneous Regression of Cancer, Cancer Energy Metabolism, Hyperglycemia-Hypoglycemia, Metformin, Warburg and Crabtree Effects and a New Perspective in Cancer Treatment. Journal of Cancer Science \& Therapy, 6, 56-61.

[17] Niakan, B. (2010) Spontaneous Remission of Cancer: Steady and Aggressive Malignant Growth Faced with Hypoxia or Hypoglycemia. Medical Hypotheses, 75, 505-506. http://dx.doi.org/10.1016/j.mehy.2010.07.006

[18] Kapelner, A. and Vorsanger, M. (2015) Starvation of Cancer via Induced Ketogenesis and Severe Hypoglycemia. Medical Hypotheses, 84, 162-168. http://dx.doi.org/10.1016/j.mehy.2014.11.002

[19] Oleksyszyn, J. (2011) The Complete Control of Glucose Level Utilizing the Composition of Ketogenic Diet with the Gluconeogenesis Inhibitor, the Anti-Diabetic Drug Metformin, as a Potential Anti-Cancer Therapy. Medical Hypotheses, 77, 171-173. http://dx.doi.org/10.1016/j.mehy.2011.04.001

[20] Violle, B., Bruno Guigas, B., Sanz Garcia, N., Leclerc, J., Foretz, M. and Andreelli, F. (2012) Cellular and Molecular Mechanisms of Metformin: An Overview. Clinical Science, 122, 253-270. http://dx.doi.org/10.1042/CS20110386

[21] Xavier, D.O., Amaral, L.S., Gomes, M.A., Rocha, M.A., Campos, P.R., Cota, B.D., et al. (2010) Metformin Inhibits Inflammatory Angiogenesis in a Murine Sponge Model. Biomedicine \& Pharmacotherapy, 64, 220-225. http://dx.doi.org/10.1016/j.biopha.2009.08.004

[22] Hirsch, H.A., Iliopoulos, D., Tsichlis, P.N. and Struhl, K. (2009) Metformin Selectively Targets Cancer Stem Cells, and Acts Together with Chemotherapy to Block Tumor Growth and Prolong Remission. Cancer Research, 69, 7507-7511.

http://dx.doi.org/10.1158/0008-5472.CAN-09-2994

[23] Janzera, A., German, N.J., Gonzalez-Herrera, K.N., Asarac, J.M., Haigis, M.C. and Struhl, K. (2014) Metformin and Phenformin Deplete Tricarboxylic Acid Cycle and Glycolytic Intermediates during Cell Transformation and NTPs in Cancer Stem Cells. Proceedings of the National Academy of Sciences of the United States of America, 111, 10574-10579. http://dx.doi.org/10.1073/pnas.1409844111

[24] Lonardo, E., Cioffi, M., Sancho, P., Sanchez-Ripoll, Y., Trabulo, S.M., Dorado, J., et al. (2013) Metformin Targets the Metabolic Achilles Heel of Human Pancreatic Cancer Stem Cells. PLoS ONE, 8, e76518. http://dx.doi.org/10.1371/journal.pone.0076518

[25] Fujimoto, N., Nakanishi, G., Kabuto, M., Nakano, T., Eto, H., Nakajima, H., Sano, S. and Tanaka, T. (2015) Merkel Cell Carcinoma Showing Regression after Biopsy: Evaluation of Programmed Cell Death 1-Positive Cells. Journal of Dermatology, 42, 496-499. http://dx.doi.org/10.1111/1346-8138.12805

[26] Herreros-Villanueva, M., Hijona, E., Cosme, A. and Bujanda, L. (2012) Spontaneous Regression of Pancreatic Cancer: Real or a Misdiagnosis? World Journal of Gastroenterology, 18, 2902-2908. http://dx.doi.org/10.3748/wjg.v18.i23.2902 
[27] Wiernik, P.H. (1976) Spontaneous Regression of Haematologic Cancers. National Cancer Institute Monograph, 44, 35-38.

[28] US Department of Health, Education and Welfare (1966) Conference on Spontaneous Regression of Cancer. Public Health Service, National Cancer Institute, Monograph 44.

[29] Beller, U., Beckman, E.M. and Twombly, G.H. (1984) Spontaneous Regression of Advanced Endometrial Carcinoma. Gynecologic Oncology, 17, 381-385. http://dx.doi.org/10.1016/0090-8258(84)90225-7

[30] Parker, R., Lanvin, D., Gilks, B. and Miller, D. (2001) Spontaneous Regression of Stage IV Clear Cell Carcinoma of the Endometrium in a Patient with Essential Thrombocytosis. $G y$ necologic Oncology, 82, 395-399. http://dx.doi.org/10.1006/gyno.2001.6273

Submit or recommend next manuscript to SCIRP and we will provide best service for you:

Accepting pre-submission inquiries through Email, Facebook, LinkedIn, Twitter, etc. A wide selection of journals (inclusive of 9 subjects, more than 200 journals)

Providing 24-hour high-quality service

User-friendly online submission system

Fair and swift peer-review system

Efficient typesetting and proofreading procedure

Display of the result of downloads and visits, as well as the number of cited articles Maximum dissemination of your research work

Submit your manuscript at: http://papersubmission.scirp.org/ 